\title{
The Emotional Intelligence and Incidence in Academic Performance for Bachelor Level
}

\author{
María Isabel Santana Vergara \\ Pontificia Universidad Católica del Ecuador, sede Manabí, Portoviejo, Ecuador \\ Corresponding author email: msantana4483@pucem.edu.ec
}

María Fernanda Argandoña Mendoza

Pontificia Universidad Católica del Ecuador, sede Manabí, Portoviejo, Ecuador

Email:margandona8801@pucem.edu.ec

\section{Rosmary Olga García Mejía}

Pontificia Universidad Católica del Ecuador, sede Manabí, Portoviejo, Ecuador

Email:rgarcia2217@pucem.edu.ec

\section{Yandri Alberto Zambrano}

Pontificia Universidad Católica del Ecuador, sede Manabí, Portoviejo, Ecuador

Email: yzambrano6546@pucem.edu.ec

\section{Maria Elena Moya Martínez}

Pontificia Universidad Católica del Ecuador, sede Manabí, Portoviejo, Ecuador

Email: mmoya@pucem.edu.ec

\begin{abstract}
The United Nations Educational and Cultural Organization, believes that one of the main axes of orientation is emotional intelligence since individual skill will depend on it; taking into account, that education is the process of formation closely related to the affectivity related to emotions. Although some authors agree in several articles, this way of discussing emotion-related abilities must have generated, in each individual, there must be that general form of knowledge and skills that make this unfold in society interacting with emotional intelligence and affective expressing concepts about the subject. One of the problems, that Emotional Inelegancy, raises is that it compares with emotional competence the ignorance of this theory has produced a great interest in the educational environment as a way of improving educational quality and socio-emotional development, several publications allege positive changes within the classroom that started. As something, empirical ended with a construct developing the theories and instruments developed by providing development in the educational community and the classroom.

Keywords---academic performance, emotional education, emotional intelligence.
\end{abstract}

\section{Introduction}

This work consists of a bibliographic review, related to emotional intelligence (EI) that incorporates theories and factors related to the subject and how it influences importantly in each student of the high school area, its positive impact on personality and especially on academic performance. Academic training requires actions, attitudes, and skills that adolescents and young people should focus on in the educational field so that they create that context of daily discipline by providing a link between their teachers, peers, the educational community, directing their healthy competence through your academic performance through the interest you exercise in the educational process. 
One of the pioneers in the educational process is parents wh. To achieve continuous work and at the same time with teachers, must stimulate the children emotionally and emotionally, so that they obtain good results in joint work with the teacher to obtain improvements both in attitude as in academic performance in students. Inside and outside the classroom, where the trilogy that focuses on teacher-parent-student, which has the same objective, has applied, so that the student can function in a competitive society. It is necessary to develop research to identify with precision the variables that influence the work of a good teacher. Some of the research on this topic concludes that not only general intelligence but also emotional and personality factors are part of the complex network of skills people face to successfully develop their professional work (Cejudo \& López-Delgado, 2017). They have expressed the ability to process emotional information and use this information as a guide for thinking and behavior (Sarrionandia \& Garaigordobil, 2017).

\section{Materials and Methods}

The study has developed the inductive method, based on references from some authors, who have treated the subject in different contexts. It being necessary to observe the field of emotional level in students implying their relationship with their academic performance, seeking to improve the use of the pedagogical process of high school, to obtain a good academic formation result of the interaction with the educational community. It is described as a theory that emerges empirically, and then take shape and become a model theory, so that the brain's intellectual coefficient and emotions generate positive changes that must be analyzed objectively, for later, allowing solutions that help in the study (Hérnandez et al., 2010). An effective study has proposed, which provokes the solution through the analysis and interpretation of the bibliographic information, intending to create situations that effectively structure the procedure and allow verifying in the context where the problem develops to examine the variables they are involved in emotional intelligence and academic performance (Moradi et al., 2011; Parker et al., 2004).

\section{Results and Discussions}

\section{Emotional intelligence}

One of the elements of greatest need in the study of emotional intelligence is empathy since it allows developing the ability to feel the emotions of those around us (Fernández \& Ramos, 2017), due to its characteristics Emotional intelligence, can be cultivated both individually and organizationally. Through a model that bets on the possibilities of changing deeply rooted behaviors and converted into routine responses, contrasting the ideal versus the real image of each individual (Goleman et al., 2016), given that it is recognized internationally by various organizations such as, for example, the Organization for Economic Cooperation and Development (OECD, 2011) states that. The changes that have occurred both in companies and in the economy are increasing emphasis on the elements of Emotional Intelligence (Fragoso, 2015).

According to Goleman (2018), emotional intelligence capabilities influence leadership styles, since leaders who used styles that positively affected the work environment obtained significantly better results. Then those who did not, therefore, it is necessary to make a comparison of how emotional intelligence affects education, considering that a teacher is the same as a manager in an organization, someone who must motivate their group to achieve favorable results (Golombek \& Doran, 2014).

For Duque et al. (2017), EI positively influences work competencies, finding that aspects such as the recognition of emotions, teamwork, communication, achievement orientation, perception, and negotiation are characteristic of the individual who favor the formation of competencies affecting work performance. Thus, for example, teachers with high EI experience greater recognition of the importance of the dimensions that make up the domain of EI to be a highly competent teacher than their colleagues with low levels (Cejudo \& López-Delgado, 2017).

In the high school period, many students go through the adolescence stage. Which is a critical period for individual and social development in which young people face various situations that put their IE and their social skills at stake (Zavala et al., 2008). The desire to unleash and be accepted causes their approaches to deviate from paying attention to their academic performance towards non-educational activities, so the inability of emotional regulation is key in this process (Andrés et al., 2017).

During this stage of development, teachers must be alert to the emotional changes of the students since that pressure that has been imposed or imposed on them raises the risk of suicide, which is associated with lower levels of emotional. Clarity and regulation and satisfaction with life, high levels of anxiety and depression (Gómez-Romero et 
al., 2018), suicide risk correlate positively and significantly with negative affect. (Depression, anxiety). Negatively with emotional clarity and regulation, and satisfaction with life that students experience regardless of their social class or geographic distribution (Santurtún et al., 2018).

Based on that, several instruments have been developed that allow students to know the degree of emotional intelligence. One of those examples is the Emotional Intelligence Test of the Botín Foundation for Adolescents (TIEFBA). A new measure of the ability to assess Intelligence, emotionality, with personal and school adjustment in adolescents (Fernández-Berrocal et al., 2018). These instruments used reflect that emotional intelligence has been influenced by age, gender, culture/religion, and the socioeconomic-cultural status of the students, evidencing that there is a statistically significant relationship between happiness and emotional intelligence, being directly proportional to the handle (Acosta \& Clavero, 2019).

Therefore, for Escobedo (2015), academic intelligence does not offer any preparation to face the problems of everyday life, with emotional intelligence being the most important, since the knowledge and management of emotions will allow a better adaptation to the environment in which each person develops. It is from there that the interest arises to relate it to variables such as personality traits, intelligence, psychological well-being, and quality of personal relationships, academic performance, leadership, and academic satisfaction.

The design and evaluation of a sequence of activities for the development of emotional and cognitive intelligence in students, to achieve comprehensive training addressing the dimensions of feeling, thinking, and acting is the alternative strategy to provide a successful emotional education (Castillo, 2010). In this way, the conception of emotional intelligence as a personality trait means that it has been considered as something important to adapt to the environment and succeed in life in a framework of psycho-pedagogical guidance for prevention and personal and social development (Fernández, 2013). Focused on positive development and competition during adolescence that refers to emotional and social content that influences intelligent behavior (González, 2016).

\section{School Performance}

The performance has continuously measured as a positive axis when the student reaches the objectives set by the teacher. It meets the expectations when the evaluative results of the educational process show that knowledge has been significant, valuing his knowledge through evaluation since what has not evaluated is devalued; therefore, an integrating environment has created, showing guidelines for improvement in academic behavior and performance (Rivera, 2018). The issue that worries teachers and parents in general, since data from several studies show results with deficits in the teaching-learning process. Where the degree of results and skills achieved by adolescents and young people is alarming and it is essential to know that, the low performance is due to several factors, which negatively influence the development of the student in the educational community.

Regarding the low school performance, several aspects have been attributed, which directly interfere with the teacher-student relationship. Also accredited family context problems, circumstances of adaptation to school, study habits, teacher methodology, economic difficulties, which paralyze significant learning within the classroom, mastery of content, and want to study; It becomes a challenge when the community does not support the educational process, adding the change that students experience in adolescence (Ruiz, 2017). Academic performance is oriented to meaningful learning, strengthening through emotional intelligence working on the acquisition of knowledge. Aimed at the interpersonal relationship and mental health where the student has that positive attitude achieving the parameters established within the teaching-learning process, Following the evaluation process if the student does not achieve the objectives set by the current school system, it is decreed as school failure.

\section{Education}

Since civilization has formed in Greece education has existed education, the great philosophers transmitted knowledge is through time have undergone a series of transformations, making it possible. The construction of knowledge focused on learning related to cultural areas (Arevalo Arboleda, 2017), being the regulatory and training entity that benefits the human being in decision-making based on personal criteria about the social relationship in the environment that develops.

According to the research carried out in Latin America, the findings show a low cultural level of parents, channeled into negative realities such as poverty, parents who have only finished primary school, this influences the performance of their children influencing future generations if, in the Currently, this wrong thinking is not changed by our society (Pinto-Archundia, 2016). Education is the main area of cultural, social, humanistic, and professional training of the human being, where parents, teachers, and students towards the teaching-learning process within the 
classroom verify the degree of the accompaniment of the educational community. Where teachers need to know the essential abilities of the student and observe a general process of achieving the planned skills in the development of activities, through a comprehensive analysis of the types of difficulties, which incur the level of learning and its impact on poor academic performance. In figure 1, observed Research on emotional intelligence for different authors.

\section{AUTORES}

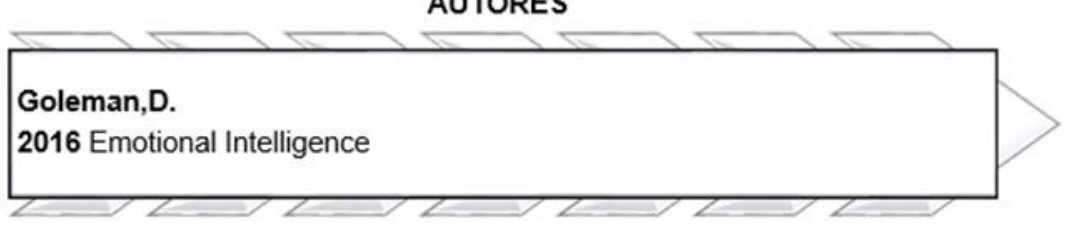

Emotional intelligence as the basis and virtue of our skills

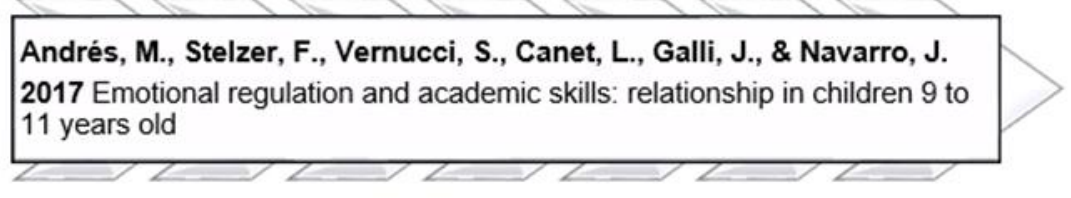

The performance of children between 9 and 11 years as a regulation of their student skills and academic skills

Pullido, F., \& Herrera, F.

2018 Relationships between happiness, emotional intelligence and sociodemographic factors in high school.

Figure 1. Criteria of different authors

Author Daniel Goleman was the one who perfected the theory of emotional intelligence. Since it was based on neurobiological studies that allow us to understand more clearly the emotional centers of the brain so that it can channel the emotions potentiating intelligence, like an IQ or IQ, using which creativity is expressed, only genetic data can modify everything and it is the vital experience which is determined by aptitude. Emotional intelligence letting emotions and feelings explore the great world of scientific psychology and part of neuroscience as a necessary condition for determining viable studies. Although not sufficient for understanding; so that it becomes a reason to see more closely the opportunities and establish law in the government of our memory and feelings. In the Nicomachean Ethics Aristotle, expresses that philosophy is a virtue of character and happiness providing wisdom to his thoughts, to work in the emotions generating the moment of creative development. Knowledge has related to learning, each individual has their way of learning or learning style, without ruling out genetic inheritance and external factors all these elements in reference would give way to creativity, relating and strengthening in the aspect of emotional intelligence.

According to Goleman (2018), emotional intelligence capabilities influence leadership styles. Since leaders who used styles that positively affected the work environment obtained significantly better results than those who did not, therefore, it is necessary to make a comparison of how emotional intelligence affects education. Considering that a teacher projects knowledge emotional intelligence may have empirically appeared in the educational field but through scientific studies and compared the results are very positive within these new theories that are gaining strength. Figure 1 shows the criteria of different authors were the origins, evolution, models, and key definitions are developed to have a broader perspective of the expression and begin to differentiate it to Andrés et al. (2017). Academic skills constitute a specific component of school success and numerous factors influence their acquisition and consolidation. One of these is the ability to regulate emotional tolerance, which has defined by the ability to resist negative emotional states in pursuit of an objective. 


\section{Conclusion}

The intensification of research on emotional intelligence is necessary to develop studies and understand the barriers that prevent students from having a good performance and influence it, learning and intelligence. Is the capacity that all human beings have; in a differentiated way it is presented through opportunities and possibilities found in the path of knowledge throughout life; where each individual interacts with society. The educational community should commit to putting emotional intelligence into practice as a basic tool in education as a multifaceted source for acquiring new knowledge and contributing to students in a positive change focused on a humanistic and integrated education allowing perspectives linked to objectives where Emotional intelligence goes hand in hand with education and its teaching-learning processes. Education has developed in students as part of the transmission of knowledge where they modify and polish it, taking and incorporating their demarcating skill and intelligence with their studies, conceiving education as a tool for improvements within their daily lives by changing the persecution on the quality and benefit of education.

\section{Acknowledgments}

The author wishes to thank Mg. María Elena Moya for her knowledge, which contributed to the construction of this research; to the IJCMS team of editorial boards for their valuable time, support, and advice to complete the present study including their collaborators and my fellow students for providing knowledge in it.

\section{References}

Acosta, F. P., \& Clavero, F. H. (2019). Relationship between happiness, emotional intelligence and sociodemographic factors in secondary education. Anuario de Psicología/The UB Journal of Psychology, 48(1), 34-42.

Andrés, ML, Stelzera, F., Vernucci, S., Canet Juric, L., Galli, JI, \& Navarro Guzmán, JI (2017). Emotion regulation and academic skills: Relationship in children aged 9 to 11. Suma Psicológica, 24 (2), 79-86.

Arevalo Arboleda, S. G. (2017). Influencing collaboration to enhance knowledge work through serendipity: userstudy and design considerations (Master's thesis).

Castillo, M. (2010). Influence of emotional intelligence in the teaching, learning and evaluation of Natural Sciences. Santiago de Cali: Universidad del Valle.

Cejudo, J., \& Luz Lopez-Delgado, M. (2017). Importance of emotional intelligence in the teaching practice: A study with primary education teachers. Psicología educativa, 23(1), 29-36.

Duque, J., Greenhouse, I., Labruna, L., \& Ivry, R. B. (2017). Physiological markers of motor inhibition during human behavior. Trends in neurosciences, 40(4), 219-236. https://doi.org/10.1016/j.tins.2017.02.006

Escobedo, P. (2015). Relationship between emotional intelligence and academic performance of the basic level students of a private school. Guatemala: Rafael Landívar University.

Fernández, M. (2013). Emotional intelligence. Class Magazine history, 1-12.

Fernández, P., \& Ramos, N. (2017). Develop your emotional intelligence. Guatemala: Editoria Kairós.

Fernández-Berrocal, P., Ruiz-Aranda, D., Salguero, J. M., Palomera, R., \& Extremera, N. (2018). The Relationship of Botín Foundation's Emotional Intelligence Test (TIEFBA) with Personal and Scholar Adjustment of Spanish Adolescents. Revista de Psicodidáctica (English ed.),23(1), 1-8. https://doi.org/10.1016/j.psicoe.2017.07.005

Fragoso, R. (2015). Emotional intelligence and emotional competencies in higher education, the same concept? Revista Iberoamericana de EducationSuperior,110-125.

Goleman, D. (2018). Emotional intelligence in the company. Spain Editorial Group.

Goleman, D., Boyatzis, R., \& McKee, A. (2016). The resonant leader creates more: The power of emotional intelligence.

Golombek, P., \& Doran, M. (2014). Unifying cognition, emotion, and activity in language teacher professional develop. https://doi.org/10.1016/j.tate.2014.01.002

Gómez-Romero, M. J., Limonero, J. T., Trallero, J. T., Montes-Hidalgo, J., \& Tomás-Sábado, J. (2018). Relationship between emotional intelligence and negative affect on suicide risk in young university students. Ansiedad $y$ Estrés, 24(1), 18-23.

González, L. (2016). Relationship between emotional intelligence, resources and psychological problems, in childhood and adolescence. Valencia: University of Valencia.

Hérnandez, R., Fernández, C., \& Baptista, M. (2010). Investigation methodology. Mexico, Mexico: Mc Graw Hill. 
Moradi, A., Pishva, N., Ehsan, H. B., \& Hadadi, P. (2011). The relationship between coping strategies and emotional intelligence. Procedia-Social and Behavioral Sciences, 30, 748-751. https://doi.org/10.1016/j.sbspro.2011.10.146

Parker, J. D., Summerfeldt, L. J., Hogan, M. J., \& Majeski, S. A. (2004). Emotional intelligence and academic success: Examining the transition from high school to university. Personality and individual differences, 36(1), 163-172. https://doi.org/10.1016/S0191-8869(03)00076-X

Pinto-Archundia, R. (2016). The Importance Of Promoting The Values Of The Home To The Elementary Schools The Importance Of Promoting The Values To Household Primary Schools. Ra Ximhai Scientific Journal , 271.

Rivera, M. (2018). Motivation and school performance in high school students, IE "José Héctor Rodríguez Trigoso". César Vallejo University, (Undergraduate thesis), Lima, Peru.

Ruiz, D. (2017). Low academic performance in the subject of mathematics, in the eighth years of basic general education at the institution "Ausubel High School". Salesian Polytechnic University, (Undergraduate Thesis), Cuenca, Ecuador.

Santurtún, M., Santurtún, A., \& Zarrabeitia, M. T. (2018). Does the environment affect suicide rates in Spain? A spatiotemporal analysis. Revista de Psiquiatría y Salud Mental (English Edition), 11(4), 192-198. https://doi.org/10.1016/j.rpsmen.2017.05.014

Sarrionandia, A., \& Garaigordobil, M. (2017). Effects of an emotional intelligence program on socioemotional factors Emotional and psychosomatic symptoms. Revista Latinoamericana de Psicología, 49(2), 110-118.

Zavala, M. A., Valadez, M. D., \& Vargas, M. C. (2008). Emotional intelligence and social skills in adolescents with high social acceptance. Electronic Journal of Research in Educational Psychology, 6(2), 319-338. 